\title{
Suicidal Ideation in a Population-Based Sample of Adolescents: Implications for Family Medicine Practice
}

\author{
Esme Fuller-Thomson, ${ }^{1}$ Gail P. Hamelin, ${ }^{2}$ and Stephen J. R. Granger ${ }^{3}$ \\ ${ }^{1}$ Factor-Inwentash Faculty of Social Work and Department of Family and Community Medicine, University of Toronto, \\ 246 Bloor Street West, Toronto, ON, Canada M5S 1A1 \\ ${ }^{2}$ Kinark Child and Family Services, 34 Simcoe Street, Suite 301, Barrie, ON, Canada L4N 6T4 \\ ${ }^{3}$ Parent and Child Capacity Building Team, Peel Children's Aid Society, 6860 Century Avenue, Mississauga, ON, Canada L5N 2 W5
}

Correspondence should be addressed to Esme Fuller-Thomson; esme.fuller.thomson@utoronto.ca

Received 28 November 2012; Accepted 23 December 2012

Academic Editors: D. Goodridge, A. M. Salinas-Martinez, and R. Snacken

Copyright (C) 2013 Esme Fuller-Thomson et al. This is an open access article distributed under the Creative Commons Attribution License, which permits unrestricted use, distribution, and reproduction in any medium, provided the original work is properly cited.

Introduction. This study investigated the relationship between suicidal ideation and demographic characteristics, health conditions, depression, and health care utilization patterns among adolescents. Methods. Secondary analysis of the regionally representative Canadian Community Health Survey conducted in 2000/2001 (response rate 85\%). Adolescents aged 15 to 19 who reported suicidal ideation in the previous year $(n=260)$ were compared with their peers who did not $(n=5528)$. The association between suicidal ideation and socio-demographic and health characteristics were investigated. Findings. Almost three-quarters (73\%) of suicidal adolescents had not spoken with any health professional about mental health issues in the preceding year. Despite the fact that $80 \%$ of suicidal adolescents had regular contact with their family doctor, only $5 \%$ had consulted with them about mental health issues. In addition to the well-known risk factors of depression and stress, suicidal ideation was highly elevated in adolescents with two or more chronic health conditions, self-reported poor health, migraines, and back pain and those whose activities were prevented by pain $(P<.05)$. Other characteristics significantly correlated with suicidal ideation included smoking, living in single parent families, and having lower levels of social support. Conclusions. Family physicians should regularly screen for suicidal thoughts in their adolescent patients with these characteristics.

\section{Introduction}

The loss of a patient, particularly an adolescent patient, to suicide is one of the most distressing events a clinician can face [1]. It is imperative that family doctors possess knowledge and understanding of the characteristics of suicidal adolescents in order to more accurately identify and intervene at an early stage. There is a significant gap in services for youth with all types of mental health issues. A recent Canadian Study showed half of suicidal adolescents had not accessed any mental health services [2]. Often the only connection these vulnerable youth have with the health care system is their family doctor.

Suicide is the third leading cause of death for teenagers in the United States [3] and the second leading cause of death for Canadian adolescents [4]. Suicide ideation and attempts are known risk factors for suicide completion [510], with an estimated 15 to 20 attempted suicides to every completed suicide [10]. Researchers note that the overall low base rate of completed suicide for youth makes it very difficult, even with a good screening tool, to predict the level of risk for completed suicide and for this reason they suggest concentrating on the phenomena associated with suicidal ideation in youth [11-13]. The prevalence of suicidal thoughts among adolescents is quite high, with an estimated $20-30 \%$ of adolescents reporting them at some point [14].

The rates at which youth present with suicidal ideation, suicide attempts, and suicide are alarmingly stable over the past twenty years. There has been extensive ongoing research $[6-10,15,16]$ into the risk factors and treatments for suicidal ideation and behavior. A systematic review of the literature concluded that there was strong evidence that the following 
factors are associated with adolescent suicidal phenomena: depression, alcohol abuse, use of hard street drugs, suicidal behavior among friends, living apart from parents, family conflict, unsupportive parents, and a history of abuse [17]. Less conclusive but promising evidence also suggests that poor physical health, sexual activity, and physical disability are associated with suicide attempts [17]. Unfortunately, there are few representative community studies discussing the use of family doctors and the use of mental health services among adolescents with suicidal ideation.

\section{Material and Methods}

2.1. Data Source. This study investigated the relationship between suicidal ideation and demographic characteristics, health conditions, psychological characteristics and health care utilization patterns among a regionally representative sample Canadians aged 15 to 19 . We also report utilization patterns of health and mental health services by Canadian adolescents with suicidal ideation. The analyses reported in this paper used the public use data files of the Canadian Community Health Survey (CCHS) conducted in 2000/2001. The target population of the CCHS covered approximately $98 \%$ of the Canadian population aged 12 or older. The CCHS had a response rate of $84.7 \%$ after 14 months of collection, which resulted in a final sample of 130,880 respondents [18]. The survey was administrated through in-home face-to-face interviews with $88 \%$ of the sample and telephone surveys conducted through home phone numbers for the remaining $12 \%$ of the sample.

Only six provinces (Nova Scotia, New Brunswick, Quebec, Ontario, Manitoba, Alberta) and one territory (Yukon) opted for the inclusion of questions on suicidal ideation. Thus, of the original 11,081 respondents aged 15 to 19 in the CCHS, only 5,788 were asked questions on suicidal ideation. These 5,788 respondents make up the sample for subsequent analyses. In the bivariate tables, we present data on several characteristics which were only asked in a sub-sample of the above provinces. Thus, self-report of life stress, hours per week watching television, whether the adolescent had ever had sexual intercourse, and levels of social support have smaller sample sizes than the other characteristics reported. These questions, in addition to income level, which had a substantial amount of missing data, were therefore excluded from the logistic regression analyses. The logistic regression analyses included 5,471 respondents who had complete data on all the variables in the analysis.

2.2. Statistical Analyses Strategy. Adolescents who reported suicidal ideation in the previous year $(n=260)$ were compared with their peers who did not $(n=5528)$. The frequency of different forms of health care utilization was reported for adolescents who had suicidal ideation. Chi-square analyses were conducted for categorical variables and independent $t$-tests were conducted for interval and ratio level variables comparing teens with and without suicidal ideation. All data were weighted to adjust for probability of selection. Two logistic regression analyses of suicidal ideation were conducted.
The first analysis included 5 demographic characteristics (gender, school attendance, race, living arrangement and whether the adolescent reported they sometimes or often did not have enough food to eat due to lack of money), 2 health behaviors (smoking status and alcohol dependency) and 6 physical health characteristics (self-perceived health status, whether their activities were prevented by pain, number of chronic conditions and whether the teenager had asthma, back problems or migraines). The second logistic regression included all of the above variables and depression.

\subsection{Measures}

2.3.1. Outcome Variable: Suicidal Ideation. Respondents in the CCHS were asked two questions on suicidal ideation: "Have you ever seriously considered committing suicide or taking your own life." Those who said yes were asked, "Has this happened in the past 12 months?" Therefore, our suicidal ideation variable was dichotomized into considered suicide in the past 12 months versus not.

2.3.2. Demographic Characteristics. In the bivariate analyses, the following demographic variables were investigated: (1) gender; (2) educational enrolment status (currently attending school/college or university versus not); (3) race (self-report: white versus non-white); (4) living arrangement (adolescent lives with two parents, with one parent, unattached, other). The "other" category includes living with a spouse and/or a child. The household's financial situation was measured in several ways: (5) Total household income. (6) Income adequacy (low, medium, high) was calculated based upon total household income and number of people in the household. (7) Extreme poverty was assessed through the question, "In the past 12 months, how often did you or anyone else in your household not have enough food to eat because of a lack of money?" (never versus sometimes or often).

2.3.3. Risk Behaviors. In several of the regions, respondents were also asked if they had ever had sexual intercourse. Smoking status identified those who had never smoked in comparison to those who were former or current smokers. Alcohol dependency was based on questions from the Composite International Diagnostic Interview-Short Form (CIDISF) developed by Kessler et al. [19]. This scale has been shown to have high sensitivity and specificity [19]. If a teenager responded that they had 5 or more drinks at least once a month during the last 12 months, they were asked a series of questions about symptoms of alcohol dependence (e.g., being drunk or hungover while at work or school or while taking care of children; experiencing a persistent desire for alcohol). If they reported at least three of these behaviors in the past month, they were classified as "alcohol dependent" [20].

\subsubsection{Physical Health Characteristics. Self-reported health} status was derived from the question "In general, would you say your health is excellent, very good, good, fair, poor." The responses were dichotomized into excellent, very good or good, versus fair or poor. The survey participants were 
asked if they were usually free of pain and discomfort. If they responded no, they were asked how many activities their pain or discomfort prevented (none, a few, some, most). The answers were then dichotomized into two categories (usually no pain or discomfort or pain prevents no activities versus pain prevents few activities, some activities or most activities). The number of chronic conditions among the CCHS respondents was calculated from summing the number of the following 17 conditions that had been diagnosed by a health professional and that had lasted six months or more: asthma, back problems, migraine headaches, arthritis or rheumatism, fibromyalgia, inflammatory bowel disease, cataracts, chronic bronchitis, emphysema or chronic obstructive pulmonary disease, diabetes, epilepsy, heart disease, cancer, stomach or intestinal ulcers, effects of a stroke, glaucoma, and chronic fatigue syndrome. These responses were summed into three categories (no chronic conditions, 1 condition, 2 or more conditions). Only the first three problems were experienced by more than $5 \%$ of $15-19$ year old respondents, and thus further analysis explored the association between each of these conditions and suicidal ideation.

2.3.5. Mental Health Characteristics. Those aged 18 and over in several of the provinces were asked about their stress level: "Thinking about the amount of stress in your life, would you say that most days are (not at all stressful, not very stressful, a bit stressful, quite a bit stressful, extremely stressful)?" The answers were dichotomized with the first three categories classified as "not stressful" and the latter two classified as "stressful".

Respondents were diagnosed as depressed if they had a probability of depression of $90 \%$ or greater as classified by Kessler and Mroczek's scale based on a subset of 21 items from the Composite International Diagnostic Interview (CIDI). The questions cover a cluster of symptoms for depressive disorder, which are listed in the 1987 Diagnostic and Statistical Manual of Mental Disorders of the American Psychiatric Association. This short-form (SF) scale was developed to operationalize Criteria A through C of the DSM-III-R diagnosis of major depressive episode. The sensitivity of the CIDI-SF was $89.6 \%$ and specificity was $93.9 \%$ with the total classification accuracy $93.2 \%$ for a major depressive episode in comparison to CIDI.

2.3.6. Characteristics of Social Support and Excessive Television Viewing. In some of the provinces, four types of social support were evaluated using the Medical Outcomes Study Social Support Survey: Emotional and informational support (e.g., empathic understanding and guidance), tangible support (e.g., material or behavioural assistance), positive social interaction (e.g., doing fun things together), and affection (e.g., love and affection). This scale had excellent reliability and validity [21]. We also investigated the association between suicidal ideation and excessive television viewing (defined as 20 or more hours per week watching television).

2.3.7. Health Care Utilization. Use of a family doctor was determined through the following question: "Not counting when you were an overnight patient in a hospital, nursing home or convalescent home, in the past 12 months, how many times have you seen, or talked on the telephone, about your physical, emotional or mental health with a family doctor or general practitioner?" Responses were dichotomized into never/ever.

Respondents' contact with mental health care professionals was determined by the question: "In the past 12 months, have you seen or talked on the telephone to a health professional about your emotional or mental health?" Those who answered yes were asked how many times they visited a mental health professional (coded as no visits, $1-3$ visits, 4 or more visits). Respondents were then asked "Whom did you see or talk to?" Family Doctor was one of several response options.

\section{Results}

As shown in Table 1, females had higher rates of suicidal ideation than males $(4.7 \%$ versus $2.9 \% ; P<.001)$. Only significant findings with $P$ values less than .05 are reported. Suicidal ideation was significantly more prevalent among those not attending school or college, unattached individuals and those living in single parent families as opposed to those living with two parents, and those who reported that they did not always have enough food to eat due to lack of money. The average household income of suicidal teenagers was significantly lower than that of their nonsuicidal peers. Each of the health risk behaviors (having had sexual intercourse, type of smoker, and alcohol dependency) was associated with an elevated prevalence of suicidal ideation. The prevalence of suicidal thoughts was higher among teens who reported poorer health status, those who had two or more chronic conditions, particularly those with migraine headaches and/or back problems, those whose activities were prevented by pain, and those who reported high levels of stress. Teenagers who were depressed had approximately ten times higher prevalence of suicidal ideation than the nondepressed $(23.1 \%$ versus $2.1 \%$ ). In comparison to adolescents without suicidal ideation, those who reported suicidal ideation had much lower levels of all four types of social support investigated. Teens who spent 20 or more hours a week watching television had almost double the prevalence of suicidal ideation in comparison to teens who did not watch as much television.

The first logistic regression analysis (which did not include the variable on depression) indicated that women had 54\% higher odds of suicidal ideation than men and that teens living in single parent households had $71 \%$ higher odds of suicidal ideation in comparison to those in two parent families (see Table 2, Model 1). Former or current smokers had five times the odds of reporting suicidal thoughts in comparison to teens who had never smoked. Adolescents who were alcohol dependent had more than twice the odds of suicidal ideation in comparison to their peers without alcohol dependency. Teens whose activities were prevented by pain had twice the odds of suicidal ideation in comparison to those without any activity limitation. According to the Nagelkerke 
TABLE 1: Bivariate analysis of suicidal ideation in 12 months preceding the survey $(n=5,788)$. Source: Canadian Community Health Survey $1.1[18]$.

\begin{tabular}{|c|c|c|c|}
\hline Variable & Total $(n)$ & \% Suicide ideation or means (SD) & $P$ value \\
\hline \multicolumn{4}{|c|}{ Demographic characteristics } \\
\hline \multicolumn{4}{|l|}{ Gender } \\
\hline Male & 2877 & $2.9 \%$ & \multirow{2}{*}{$<.001$} \\
\hline Female & 2911 & $4.7 \%$ & \\
\hline \multicolumn{4}{|l|}{ Currently attending school/college } \\
\hline Yes & 4480 & $3.3 \%$ & \multirow{2}{*}{$<.001$} \\
\hline No & 1308 & $5.9 \%$ & \\
\hline \multicolumn{4}{|l|}{ Race (Self-report) } \\
\hline Non-white & 691 & $2.8 \%$ & \multirow{2}{*}{.07} \\
\hline White & 5006 & $4.0 \%$ & \\
\hline \multicolumn{4}{|l|}{ Living arrangement } \\
\hline Child with 2 parents & 3781 & $2.9 \%$ & \multirow{4}{*}{$<.001$} \\
\hline Child with single parent & 713 & $6.0 \%$ & \\
\hline Unattached & 448 & $6.5 \%$ & \\
\hline Other & 767 & $4.6 \%$ & \\
\hline \multicolumn{4}{|l|}{$\begin{array}{l}\text { Total household income } \\
\text { mean (S.D) }\end{array}$} \\
\hline Not suicidal & 4716 & $\$ 55,860(\$ 27,210)$ & \multirow{2}{*}{$<.001$} \\
\hline Suicidal & 222 & $\$ 48,780(\$ 26,175)$ & \\
\hline \multicolumn{4}{|l|}{ Income adequacy } \\
\hline Low & 668 & $5.1 \%$ & \multirow{3}{*}{.12} \\
\hline Middle & 1197 & $3.8 \%$ & \\
\hline High & 3094 & $3.4 \%$ & \\
\hline \multicolumn{4}{|l|}{ Not enough to eat due to lack of money } \\
\hline Always enough food & 5234 & $3.7 \%$ & \multirow{2}{*}{.01} \\
\hline Sometimes/often not enough & 504 & $6.1 \%$ & \\
\hline \multicolumn{4}{|c|}{ Risk behaviours } \\
\hline \multicolumn{4}{|l|}{ Had sexual intercourse } \\
\hline Yes & 821 & $7.1 \%$ & \multirow{2}{*}{$<.001$} \\
\hline No & 1197 & $2.1 \%$ & \\
\hline \multicolumn{4}{|l|}{ Type of smoker } \\
\hline Never smoked & 2780 & $1.2 \%$ & \multirow{2}{*}{$<.001$} \\
\hline Former or current smoker & 2978 & $6.9 \%$ & \\
\hline \multicolumn{4}{|l|}{ Alcohol dependency } \\
\hline Not dependent & 5440 & $3.5 \%$ & \multirow{2}{*}{$<.001$} \\
\hline Dependent & 288 & $13.6 \%$ & \\
\hline \multicolumn{4}{|c|}{ Physical health } \\
\hline \multicolumn{4}{|l|}{ Self-perceived health } \\
\hline Excellent/good health & 5497 & $3.6 \%$ & \multirow{2}{*}{$<.001$} \\
\hline Fair/poor health & 291 & $8.7 \%$ & \\
\hline \multicolumn{4}{|l|}{ Activities prevented by pain } \\
\hline No activities prevented & 5567 & $3.5 \%$ & $<.001$ \\
\hline Some activities prevented by pain & 216 & $12.6 \%$ & \\
\hline
\end{tabular}


TABle 1: Continued.

\begin{tabular}{|c|c|c|c|}
\hline Variable & Total $(n)$ & $\%$ Suicide ideation or means (SD) & $P$ value \\
\hline \multicolumn{4}{|c|}{ Number of chronic conditions } \\
\hline No conditions & 4216 & $3.3 \%$ & \multirow{3}{*}{$<.001$} \\
\hline 1 condition & 1189 & $3.8 \%$ & \\
\hline 2 or more conditions & 376 & $10.6 \%$ & \\
\hline \multicolumn{4}{|l|}{ Has Asthma } \\
\hline No & 5058 & $3.7 \%$ & \multirow{2}{*}{.16} \\
\hline Yes & 729 & $4.8 \%$ & \\
\hline \multicolumn{4}{|l|}{ Has back problems } \\
\hline No & 5306 & $3.5 \%$ & \multirow{2}{*}{$<.001$} \\
\hline Yes & 482 & $7.6 \%$ & \\
\hline \multicolumn{4}{|l|}{ Has migraine headaches } \\
\hline No & 5363 & $3.6 \%$ & \multirow{2}{*}{$<.001$} \\
\hline Yes & 425 & $7.2 \%$ & \\
\hline \multicolumn{4}{|c|}{ Mental health } \\
\hline \multicolumn{4}{|l|}{ Life stress } \\
\hline Not at all/a bit & 1874 & $3.2 \%$ & \multirow{2}{*}{.02} \\
\hline Quite a bit/extremely & 403 & $5.5 \%$ & \\
\hline \multicolumn{4}{|l|}{ Depression } \\
\hline No & 5257 & $2.1 \%$ & \multirow{2}{*}{$<.001$} \\
\hline Yes & 512 & $23.1 \%$ & \\
\hline \multicolumn{4}{|c|}{ Social support } \\
\hline \multicolumn{4}{|c|}{$\begin{array}{l}\text { Emotional/informational support } \\
\text { mean (S.D.) }\end{array}$} \\
\hline Nonsuicidal & 3910 & $28.1(4.9)$ & \multirow{2}{*}{$<.001$} \\
\hline Suicidal & 182 & $24.7(7.2)$ & \\
\hline \multicolumn{4}{|l|}{$\begin{array}{l}\text { Positive social interaction } \\
\text { Mean (S.D.) }\end{array}$} \\
\hline Nonsuicidal & 3917 & $14.4(2.3)$ & \multirow{2}{*}{$<.001$} \\
\hline Suicidal & 183 & $13.3(2.9)$ & \\
\hline \multicolumn{4}{|l|}{$\begin{array}{l}\text { Affection } \\
\text { mean (S.D.) }\end{array}$} \\
\hline Nonsuicidal & 3918 & $10.7(1.9)$ & \multirow[t]{2}{*}{$<.001$} \\
\hline Suicidal & 184 & $9.4(3.0)$ & \\
\hline \multicolumn{4}{|l|}{$\begin{array}{l}\text { Tangible social support } \\
\text { Mean (S.D.) }\end{array}$} \\
\hline Nonsuicidal & 3922 & $14.3(2.4)$ & \multirow{2}{*}{$<.001$} \\
\hline Suicidal & 184 & $13.0(3.2)$ & \\
\hline \multicolumn{4}{|l|}{ Hours/week watching TV } \\
\hline 0-20 hours & 2380 & $3.4 \%$ & \multirow{2}{*}{$<.01$} \\
\hline$>20$ hours & 485 & $6.3 \%$ & \\
\hline
\end{tabular}

R-square statistic, the variables in the first model explained $12.7 \%$ of the variability in suicidal ideation, which increased to $22.9 \%$ when depression was added to the model (please see Table 2, Model 2). Those who were depressed had nine times the odds of reporting that they had suicidal thoughts in the preceding year when compared with their nondepressed peers. Once depression was included in the model, only two other characteristics remained statistically significant: living in a single parent family and smoking status.
Our univariate analyses of health care utilization indicated that suicidal adolescents were not getting the help they needed: almost three-quarters (73\%) of suicidal adolescents had not spoken about mental health issues with any health professional (including family doctors, psychiatrists, psychologists and/or social workers). Only $18 \%$ of suicidal teens had four or more mental health visits with any health professional. Our particular interest was to focus on the use of family doctors by teens with suicidal ideations. Although $80 \%$ 
TABLE 2: Logistic regression analysis of suicidal ideation in 12 months preceding the survey $(n=5,471)$. Source: Canadian Community Health Survey $1.1[18]$.

\begin{tabular}{|c|c|c|c|c|}
\hline Variable & $\begin{array}{l}\text { Model 1: Odds } \\
\text { ratio depression } \\
\text { excluded }\end{array}$ & $\begin{array}{c}95 \% \\
\text { Confidence } \\
\text { Interval }\end{array}$ & $\begin{array}{l}\text { Model 2: Odds } \\
\text { ratio depression } \\
\text { included }\end{array}$ & $\begin{array}{c}95 \% \\
\text { Confidence } \\
\text { Interval } \\
\end{array}$ \\
\hline \multicolumn{5}{|c|}{ Demographic characteristics } \\
\hline \multicolumn{5}{|l|}{ Gender } \\
\hline Male & 1.00 & Reference & 1.00 & Reference \\
\hline Female & 1.54 & $(1.15,2.08)$ & 1.07 & $(0.78,1.47)$ \\
\hline \multicolumn{5}{|l|}{$\begin{array}{l}\text { Currently attending } \\
\text { school/college }\end{array}$} \\
\hline Yes & 1.00 & Reference & 1.00 & Reference \\
\hline No & 1.18 & $(0.85,1.64)$ & 1.17 & $(0.83,1.64)$ \\
\hline \multicolumn{5}{|l|}{ Race (Self-report) } \\
\hline Non-white & 1.00 & Reference & 1.00 & Reference \\
\hline White & 1.02 & $(0.66,1.59)$ & 1.09 & $(0.69,1.73)$ \\
\hline \multicolumn{5}{|l|}{ Living arrangement } \\
\hline Child with 2 parents & 1.00 & Reference & 1.00 & Reference \\
\hline Child with single parent & 1.71 & $(1.18,2.46)$ & 1.70 & $(1.16,2.48)$ \\
\hline Unattached & 1.37 & $(0.85,2.21)$ & 1.20 & $(0.73,1.99)$ \\
\hline Other & 1.01 & $(0.66,1.54)$ & 1.06 & $(0.68,1.66)$ \\
\hline \multicolumn{5}{|l|}{$\begin{array}{l}\text { Not enough to eat due } \\
\text { to lack of money }\end{array}$} \\
\hline Always enough food & 1.00 & Reference & 1.00 & Reference \\
\hline Sometimes/often not enough & 1.15 & $(0.74,1.77)$ & 0.82 & $(0.51,1.31)$ \\
\hline \multicolumn{5}{|c|}{ Risk behaviours } \\
\hline \multicolumn{5}{|l|}{ Smoking status } \\
\hline Never smoked & 1.00 & Reference & 1.00 & Reference \\
\hline Former or current smoker & 5.03 & $(3.41,7.40)$ & 4.21 & $(2.84,6.23)$ \\
\hline \multicolumn{5}{|l|}{ Alcohol dependency } \\
\hline Not dependent & 1.00 & Reference & 1.00 & Reference \\
\hline Dependent & 2.27 & $(1.43,3.56)$ & 1.48 & $(0.90,2.43)$ \\
\hline \multicolumn{5}{|c|}{ Physical health } \\
\hline \multicolumn{5}{|l|}{ Self-perceived health } \\
\hline Excellent/good health & 1.00 & Reference & 1.00 & Reference \\
\hline Fair/poor health & 1.53 & $(0.94,2.50)$ & 1.30 & $(0.77,2.19)$ \\
\hline \multicolumn{5}{|l|}{ Activities prevented by pain } \\
\hline No activities prevented & 1.00 & Reference & 1.00 & Reference \\
\hline $\begin{array}{l}\text { Some activities prevented } \\
\text { by pain }\end{array}$ & 1.99 & $(1.18,3.36)$ & 1.64 & $(0.93,2.90)$ \\
\hline \multicolumn{5}{|l|}{ Number of chronic conditions } \\
\hline No conditions & 1.00 & Reference & 1.00 & Reference \\
\hline 1 condition & 0.84 & $(0.48,1.49)$ & 0.83 & $(0.46,1.48)$ \\
\hline 2 or more conditions & 1.34 & $(0.50,3.56)$ & 1.06 & $(0.37,3.05)$ \\
\hline \multicolumn{5}{|l|}{ Has asthma } \\
\hline No & 1.00 & Reference & 1.00 & Reference \\
\hline Yes & 1.05 & $(0.57,1.94)$ & 0.95 & $(0.50,1.82)$ \\
\hline \multicolumn{5}{|l|}{ Has back problems } \\
\hline No & 1.00 & Reference & 1.00 & Reference \\
\hline Yes & 1.28 & $(0.67,2.45)$ & 1.31 & $(0.66,2.60)$ \\
\hline
\end{tabular}


TABLE 2: Continued.

\begin{tabular}{|c|c|c|c|c|}
\hline Variable & $\begin{array}{c}\text { Model 1: Odds } \\
\text { ratio depression } \\
\text { excluded }\end{array}$ & $\begin{array}{c}95 \% \\
\text { Confidence } \\
\text { Interval } \\
\end{array}$ & $\begin{array}{l}\text { Model 2: Odds } \\
\text { ratio depression } \\
\text { included }\end{array}$ & $\begin{array}{c}95 \% \\
\text { Confidence } \\
\text { Interval } \\
\end{array}$ \\
\hline \multicolumn{5}{|l|}{ Has migraine headaches } \\
\hline No & 1.00 & Reference & 1.00 & Reference \\
\hline Yes & 1.35 & $(0.71,2.56)$ & 1.25 & $(0.64,2.45)$ \\
\hline \multicolumn{5}{|c|}{ Mental health } \\
\hline \multicolumn{5}{|l|}{ Depression } \\
\hline No & - & - & 1.00 & Reference \\
\hline Yes & & & 8.97 & $(6.49,12.40)$ \\
\hline \multicolumn{5}{|c|}{ Model characteristics } \\
\hline Chi-Square of the model & 197.7 & & 360.1 & \\
\hline$P$ value of the model & $P<.001$ & & $P<.001$ & \\
\hline $\begin{array}{l}\text { Nagelkerke } \\
\text { Pseudo } R \text {-Square }\end{array}$ & .127 & & .229 & \\
\hline
\end{tabular}

of suicidal adolescents reported that they had seen or spoken on the phone with their family doctor in the preceding year about any issue, only 5\% indicated that they had consulted with their family doctor about a mental health issue.

\section{Discussion}

The vast majority of suicidal teens were not receiving any mental health services from health professionals. Our finding that only $27 \%$ of suicidal adolescents had consulted with any mental health professional in the past year is comparable to Wilson's finding that only 1 in 4 adolescents with a mental health problem seek medical care to address the problem [12].

Four out of five suicidal teens had seen or talked on the phone with their family doctor in the past year, presenting an important opportunity to discuss mental health concerns. Apparently, the majority of adolescents with suicidal ideation did not present these issues: only one in twenty suicidal teens reported that they had spoken to their family doctor about mental health concerns. Although general practitioners (GP), such as family practitioners, are often the first point of contact for adolescents seeking health care, barriers to accessing mental health assistance from GPs include "limited knowledge about the types of help GPs provide; perceived difficulties in the doctor-patient relationship; fears about both the process and content of a GP consultation" [12, p. 345]; and difficulties accessing services [22]. Literature suggests that parents' and youth's perceptions of a mental health problem affect whether youth access mental health services [23]. Barriers to service use include beliefs that the mental health problem is not serious enough and a desire to solve the problem oneself [23]. When these barriers can be overcome, research has found that youths are often more comfortable discussing issues with their GP than with a specialist [24].

Therefore, it appears that the health professional must take the initiative to investigate potential suicidality among their adolescent patients. A recent study concluded that GPs do not routinely ask adolescent patients about suicidal ideation and often lack time to properly screen patients [24]. Researchers have proposed that medical practitioners take individualized approaches with clients to focus on their unique strengths, vulnerabilities, and specific circumstances when assessing suicidality [25]. Improved knowledge about the characteristics associated with elevated risk of suicidal ideation could improve targeting and outreach efforts by family physicians.

In identifying their most vulnerable teen patients, the findings of our population-based study indicate that doctors may benefit from considering suicidal risk factors in addition to the usual "red flags" of depression [17] and stress [26]. Of particular relevance to family physicians, suicidal ideation was significantly elevated in teens with back problems and/migraine headaches, two or more chronic conditions, and poor self-reported health. Other studies have identified chronic illness as a risk factor for adolescent suicidal ideation $[27,28]$, particularly when comorbid with depression [29]. In a prospective study [30], migraines have been found to be an independent factor associated with suicide attempts, even in the absence of a major depressive disorder. Our finding that those whose activities were prevented by pain had more than triple the prevalence of suicidal ideation in comparison to those without activity limitations (12.6\% versus $3.5 \%$ ) builds on previous research showing positive associations between suicidal ideation and pain intensity [31] and chronic pain $[32,33]$, although the link between suicidality and both back pain and activity limitation due to pain have not been as extensively studied in the adolescent population.

Additionally, women, teens from single parent families, those without adequate food due to financial problems, smokers, and those who were sexually active had a high prevalence of suicidal ideation as did those with low levels of social support. Family physicians could target adolescent patients with these mental health, health, and sociodemographic characteristics for sensitive assessment of suicidal risk as an important first step in improving services to these vulnerable and underserved adolescents. 
In keeping with the previous research, we found female adolescents had much higher risk of suicidal thoughts than their male peers. The risk ratio in this study was 1.62 , very similar to that found in the average of 5 previous studies on the phenomenon $(1.58,95 \%$ C.I. 1.50 to 1.67$)$ [14]. While females have higher risks of suicidal thoughts, plans, and attempts, it is, in fact, adolescent males who have much higher rates of suicide completion [34].

Our findings that $2.9 \%$ of males aged 15 to 19 and $4.7 \%$ of female adolescents reported suicidal thoughts in the previous year was well below the average found in other studies (19.3\%, $95 \%$ C.I. $11.7 \%$ to $27 \%$ at some point in a 12 month period) [35]. There are several possible reasons for this: interview surveys (such as the CCHS) typically report much lower rates of all suicidal phenomena than anonymous questionnaires [35]. Furthermore, the vast majority of the previous studies had been school based, not community based [35]. It is probable that adolescents are less likely to report suicidal thoughts when interviewed in their home environment than in a school setting.

We found a positive correlation between a number of health risk behaviors and suicidal ideation which had also been identified in other studies. These factors include smoking [36, 37], sexual activity and alcohol dependency. Evidence suggests that smoking mediates other psychosocial causes of suicidal ideation (e.g., depression) and is likely not a causal pathway [37]. Other researchers have also shown that among adolescent females, sexual activity and sexual risk-taking is associated with increased suicidal ideation and suicide attempts [36, 38-43]. Both male and female adolescents who used alcohol at the time of sexual intercourse were found to have greater odds of considering a suicide attempt [36]. Within the adolescent population, sexual risk-taking behavior has been identified as a psychosocial and behavioral risk factor interrelated with suicidal ideation.

We found that not attending school was associated with much higher rates of suicidal ideation, a finding that replicated earlier research [44]. Depression, however, is also highly correlated with school drop-out and thus it is unclear whether the relationship is direct or indirect. Living arrangement was also a significant factor. Previous research [45] supports our finding that those who lived with neither parent had higher levels of suicidal ideation than those living in two parent families. However, our finding that adolescents from single parent families had higher suicidal ideation rates than those in two parent families is in keeping with some earlier research for example, [46], but in contrast to others (e.g., [45]).

We found that suicidal ideation was higher in those with lower household income, measured in dollars, and those with insufficient food due to economic problems. However, when income was divided into low, medium, and high categories, we did not find a significant association with suicidal ideation. The association between poverty and suicidal ideation may result from the increased stress and higher level of hopelessness among those in extreme financial need $[47,48]$. Other studies suggest that it is particularly food insufficiency, and not low income levels in general, which is strongly correlated to dysthymia, suicidal ideation, and suicide attempts [49].

Evidence suggests that individuals often use entertainment media when experiencing stress and anxiety [50], and when feeling lonely [51]. In their nationally representative study, Bickham and Rich [52] found that children who spent more time watching violent television alone spent less non-television time with friends. Our study indicated a significantly higher prevalence of suicidal ideation among those watching television more than 20 hours per week. Our data do not allow us to know if those with excessive television viewing were socially isolated or lonely. In future research on adolescents and suicidality, attention to high levels of media exposure and its potential link to social isolation would be helpful. Research suggests the importance of understanding the role of social integration and isolation with suicidal behaviour [53]. A number of studies have found social isolation to be associated with increased risk of suicide attempts [54] and suicidal ideation $[55,56]$.

Adolescents in the present study who reported suicidal ideation had low levels of all four types of social support. This finding supports previous studies that have found social support to be a protective factor against suicidality [57-59], particularly perceived parental support $[57,58]$.

In our study, $10.2 \%$ of the variability in suicidal ideation was explained by depression, even after a wide range of other risk factors had been included in the analysis. Other researchers have also emphasized that presence of a depressive mood disorder is among the most powerful predictors of suicidal ideation and suicide attempt [60]. Further elevations in the risk for suicidal behavior occurs when depression or affective disorders are present in combination with substance abuse [61-64]. However, it is positive to note that three quarters of the depressed respondents were not suicidal. Future research efforts could focus on reasons why some depressed adolescents are suicidal while the majority are not in order to inform strategies to decrease the prevalence of suicidal ideation. A major limitation of our study was the lack of data in the CCHS on several important risk factors for suicidal ideation including homosexuality and bisexuality [65] and whether the teen had a peer or family member who had attempted suicide [17].

\section{Conclusion}

Family doctors are suicidal adolescents' major point of contact with the health care system. Although four out of five suicidal teens had met with a family physician in the year preceding the survey, only one in twenty had discussed any mental health concerns with their family doctor. Clearly, the onus is on the family doctor to initiate discussions related to depression and suicidal thoughts because teenagers rarely disclose these issues to their doctors without prompting. This study provides a profile of teens most at risk for suicidal ideation, which should improve targeting and outreach to the most vulnerable. In addition to the well-known risk factors of depression and stress, suicidal ideation was highly elevated in adolescents with two or more chronic health conditions, 
self-reported poor health, migraines, and those whose activities were prevented by pain. Teens with these conditions are likely to be heavier users of family medicine services. Other characteristics significantly correlated with suicidal ideation include lower income, smoking, living alone or in single parent families, having lower levels of social support, and watching excessive amounts of television. Family physicians should regularly screen for suicidal thoughts in their adolescent patients with these characteristics in order to intervene as early as possible.

\section{Acknowledgments}

This research was undertaken, in part, thanks to support for E. Fuller-Thomson from the Sandra Rotman Endowed Chair at the University of Toronto. The authors would like to thank Marla Battiston and Sarah Brennenstuhl for their help with paper preparation.

\section{References}

[1] C. Campbell and T. Fahy, "The role of the doctor when a patient commits suicide," The Psychiatrist, vol. 26, pp. 44-49, 2002.

[2] A. H. Cheung and C. S. Dewa, "Mental health service use among adolescents and young adults with major depressive disorder and suicidality," The Canadian Journal of Psychiatry, vol. 52, no. 4, pp. 228-232, 2007.

[3] A. M. Miniño, "Mortality among teenagers aged 12-19 years: United States, 1999-2006," NCHS Data Brief, vol. 37, 2010, http://www.cdc.gov/nchs/data/databriefs/db37.htm.

[4] Canadian Mental Health Association, "Suicide statistics," 2006, http://www.ontario.cmha.ca/fact_sheets.asp?cID=3965.

[5] D. M. Adams, J. C. Overholser, and A. Spirito, "Stressful life events associated with adolescent suicide attempts," The Canadian Journal of Psychiatry, vol. 39, no. 1, pp. 43-48, 1994.

[6] D. A. Brent, M. Oquendo, B. Birmaher et al., "Familial pathways to early-onset suicide attempt: risk for suicidal behavior in offspring of mood-disordered suicide attempters," Archives of General Psychiatry, vol. 59, no. 9, pp. 801-807, 2002.

[7] B. J. Cox, M. W. Enns, and I. P. Clara, "Psychological dimensions associated with suicidal ideation and attempts in the national comorbidity survey," Suicide and Life-Threatening Behavior, vol. 34, no. 3, pp. 209-219, 2004.

[8] R. K. Oates, "Sexual abuse and suicidal behavior," Child Abuse and Neglect, vol. 28, no. 5, pp. 487-489, 2004.

[9] M. Séguin, J. Lynch, R. Labelle, and A. Gagnon, "Personal and family risk factors for adolescent suicidal ideation and attempts," Archives of Suicide Research, vol. 8, no. 3, pp. 227-238, 2004.

[10] A. Spirito and J. Overholser, "The suicidal child: assessment and management of adolescents after a suicide attempt," Child and Adolescent Psychiatric Clinics of North America, vol. 12, no. 4, pp. 649-665, 2003.

[11] P. M. Lewinsohn, P. Rohde, and J. R. Seeley, "Psychosocial risk factors for future adolescent suicide attempts," Journal of Consulting and Clinical Psychology, vol. 62, no. 2, pp. 297-305, 1994.

[12] C. J. Wilson, F. P. Deane, K. L. Marshall, and A. Dalley, "Adolescents' suicidal thinking and reluctance to consult general medical practitioners," Journal of Youth and Adolescence, vol. 39, no. 4, pp. 343-356, 2010.

[13] C. J. Wilson and F. P. Deane, "Help-negation and suicidal ideation: the role of depression, anxiety and hopelessness," Journal of Youth and Adolescence, vol. 39, no. 3, pp. 291-305, 2010.

[14] E. Evans, K. Hawton, K. Rodham, and J. Deeks, “The prevalence of suicidal phenomena in adolescents: a systematic review of population-based studies," Suicide and Life-Threatening Behavior, vol. 35, no. 3, pp. 239-250, 2005.

[15] D. A. Brent, J. A. Perper, G. Moritz et al., "Psychiatric risk factors for adolescent suicide: a case-control study," Journal of the American Academy of Child and Adolescent Psychiatry, vol. 32, no. 3, pp. 521-529, 1993.

[16] P. S. Links, B. Gould, and R. Ratnayake, "Assessing suicidal youth with antisocial, borderline, or narcissistic personality disorder," The Canadian Journal of Psychiatry, vol. 48, no. 5, pp. 301-310, 2003.

[17] E. Evans, K. Hawton, and K. Rodham, "Factors associated with suicidal phenomena in adolescents: a systematic review of population-based studies," Clinical Psychology Review, vol. 24, no. 8, pp. 957-979, 2004.

[18] Y. Beland, "Canadian community health survey: methodological overview," Health Reports, vol. 13, no. 3, pp. 9-14, 2002.

[19] R. C. Kessler, G. Andrews, D. Mroczek, B. Uston, and H. Wittchen, "The world health organization composite international diagnostic interview short form (CIDI-SF)," International Journal of Methods in Psychiatric Research, vol. 7, no. 4, pp. 171-185, 1998.

[20] R. C. Kessler, K. A. McGonagle, S. Zhao et al., "Lifetime and 12 -month prevalence of DSM-III-R psychiatric disorders in the United States: results from the national comorbidity survey," Archives of General Psychiatry, vol. 51, no. 1, pp. 8-19, 1994.

[21] C. D. Sherbourne and A. L. Stewart, "The MOS social support survey," Social Science and Medicine, vol. 32, no. 6, pp. 705-714, 1991.

[22] C. J. Wilson, F. P. Deane, K. L. Marshall, and A. Dalley, "Reducing adolescents' perceived barriers to treatment and increasing help-seeking intentions: effects of classroom presentations by general practitioners," Journal of Youth and Adolescence, vol. 37, no. 10, pp. 1257-1269, 2008.

[23] M. S. Gould, F. A. Marrocco, K. Hoagwood, M. Kleinman, L. Amakawa, and E. Altschuler, "Service use by at-risk youths after school-based suicide screening," Journal of the American Academy of Child and Adolescent Psychiatry, vol. 48, no. 12, pp. 1193-1201, 2009.

[24] W. Gardner, J. Klima, D. Chisolm et al., "Screening, triage, and referral of patients who report suicidal thought during a primary care visit," Pediatrics, vol. 125, no. 5, pp. 945-952, 2010.

[25] J. G. Fiedorowicz, K. Weldon, and G. Bergus, "Determining suicide risk (hint: a screen is not enough)," Journal of Family Practice, vol. 59, no. 5, pp. 256-260, 2010.

[26] K. E. Grover, K. L. Green, J. W. Pettit, L. L. Monteith, M. J. Garza, and A. Venta, "Problem solving moderates the effects of life event stress and chronic stress on suicidal behaviors in adolescence," Journal of Clinical Psychology, vol. 65, no. 12, pp. 1281-1290, 2009.

[27] W. G. Reiner, J. P. Gearhart, and B. Kropp, "Suicide and suicidal ideation in classic exstrophy," Journal of Urology, vol. 180, no. 4, pp. 1661-1664, 2008. 
[28] J. C. Surís, N. Parera, and C. Puig, "Chronic illness and emotional distress in adolescence," Journal of Adolescent Health, vol. 19, no. 2, pp. 153-156, 1996.

[29] L. Haarasilta, M. Marttunen, J. Kaprio, and H. Aro, "Major depressive episode and physical health in adolescents and young adults: results from a population-based interview survey," European Journal of Public Health, vol. 15, no. 5, pp. 489-493, 2005.

[30] N. Breslau and G. C. Davis, "Migraine, physical health and psychiatric disorder: a prospective epidemiologic study in young adults," Journal of Psychiatric Research, vol. 27, no. 2, pp. 211-221, 1993.

[31] M. T. Smith, R. R. Edwards, R. C. Robinson, and R. H. Dworkin, "Suicidal ideation, plans, and attempts in chronic pain patients: factors associated with increased risk," Pain, vol. 111, no. 1-2, pp. 201-208, 2004.

[32] G. E. Ratcliffe, M. W. Enns, S. L. Belik, and J. Sareen, "Chronic pain conditions and suicidal ideation and suicide attempts: an epidemiologic perspective," Clinical Journal of Pain, vol. 24, no. 3, pp. 204-210, 2008.

[33] B. S. Hinkley and M. E. Jaremko, "Effects of pain duration on psychosocial adjustment in orthopedic patients: the importance of early diagnosis and treatment of pain," Journal of Pain and Symptom Management, vol. 9, no. 3, pp. 175-185, 1994.

[34] S. S. Canetto and I. Sakinofsky, "The gender paradox in suicide," Suicide and Life-Threatening Behavior, vol. 28, no. 1, pp. 1-23, 1998.

[35] E. Evans, K. Hawton, and K. Rodham, "Suicidal phenomena and abuse in adolescents: a review of epidemiological studies," Child Abuse and Neglect, vol. 29, no. 1, pp. 45-58, 2005.

[36] J. A. Epstein and A. Spirito, "Gender-specific risk factors for suicidality among high school students," Archives of Suicide Research, vol. 14, no. 3, pp. 193-205, 2010.

[37] J. M. Hockenberry, E. J. Timmons, and M. V. Weg, "Smoking, parent smoking, depressed mood, and suicidal ideation in teens," Nicotine and Tobacco Research, vol. 12, no. 3, pp. 235-242, 2010.

[38] D. D. Hallfors, M. W. Waller, C. A. Ford, C. T. Halpern, P. H. Brodish, and B. Iritani, "Adolescent depression and suicide risk: association with sex and drug behavior," American Journal of Preventive Medicine, vol. 27, no. 3, pp. 224-231, 2004.

[39] R. A. King, M. Schwab-Stone, A. J. Flisher et al., "Psychosocial and risk behavior correlates of youth suicide attempts and suicidal ideation," Journal of the American Academy of Child and Adolescent Psychiatry, vol. 40, no. 7, pp. 837-846, 2001.

[40] T. Luster and S. Small, "Factors associated with sexual risktaking behaviors among adolescents," Journal of Marriage and the Family, vol. 56, no. 3, pp. 622-632, 1994.

[41] R. A. Vannatta, "Risk factors related to suicidal behavior among male and female adolescents," Journal of Youth and Adolescence, vol. 25, no. 2, pp. 149-160, 1996.

[42] B. M. Wagner, R. E. Cole, and P. Schwartzman, "Psychosocial correlates of suicide attempts among junior and senior high school youth," Suicide and Life-Threatening Behavior, vol. 25, no. 3, pp. 358-372, 1995.

[43] L. G. Wild, A. J. Flisher, A. Bhana, and C. Lombard, "Associations among adolescent risk behaviours and self-esteem in six domains," Journal of Child Psychology and Psychiatry and Allied Disciplines, vol. 45, no. 8, pp. 1454-1467, 2004.

[44] E. A. Thompson, K. A. Moody, and L. L. Eggert, "Discriminating suicide ideation among high-risk youth," The Journal of School Health, vol. 64, no. 9, pp. 361-367, 1994.
[45] R. Kaltiala-Heino, M. Rimpelä, P. Rantanen, and P. Laippala, "Adolescent depression: the role of discontinuities in life course and social support," Journal of Affective Disorders, vol. 64, no. 23, pp. 155-166, 2001.

[46] H. Z. Reinherz, R. M. Giaconia, A. B. Silverman et al., "Early psychosocial risks for adolescent suicidal ideation and attempts," Journal of the American Academy of Child and Adolescent Psychiatry, vol. 34, no. 5, pp. 599-611, 1995.

[47] J. M. Bolland, "Hopelessness and risk behaviour among adolescents living in high-poverty inner-city neighbourhoods," Journal of Adolescence, vol. 26, no. 2, pp. 145-158, 2003.

[48] J. P. Shonkoff, W. T. Boyce, and B. S. McEwen, "Neuroscience, molecular biology, and the childhood roots of health disparities: building a new framework for health promotion and disease prevention," The Journal of the American Medical Association, vol. 301, no. 21, pp. 2252-2259, 2009.

[49] K. Alaimo, C. M. Olson, and E. A. Frongillo, "Family food insufficiency, but not low family income, is positively associated with dysthymia and suicide symptoms in adolescents," Journal of Nutrition, vol. 132, no. 4, pp. 719-725, 2002.

[50] D. N. Greenwood, "Television as escape from self: psychological predictors of media involvement," Personality and Individual Differences, vol. 44, no. 2, pp. 414-424, 2008.

[51] D. N. Greenwood and C. R. Long, "Psychological predictors of media involvement: solitude experiences and the need to belong," Communication Research, vol. 36, no. 5, pp. 637-654, 2009.

[52] D. S. Bickham and M. Rich, "Is television viewing associated with social isolation? Roles of exposure time, viewing context, and violent content," Archives of Pediatrics and Adolescent Medicine, vol. 160, no. 4, pp. 387-392, 2006.

[53] C. A. King and C. R. Merchant, "Social and interpersonal factors relating to adolescent suicidality: a review of the literature," Archives of Suicide Research, vol. 12, no. 3, pp. 181-196, 2008.

[54] D. L. Haynie, S. J. South, and S. Bose, "Residential mobility and attempted suicide among adolescents: an individual-level analysis," Sociological Quarterly, vol. 47, no. 4, pp. 693-721, 2006.

[55] P. S. Bearman and J. Moody, "Suicide and friendships among American adolescents," American Journal of Public Health, vol. 94, no. 1, pp. 89-95, 2004.

[56] R. E. Roberts, C. R. Roberts, and Y. R. Chen, "Suicidal thinking among adolescents with a history of attempted suicide," Journal of the American Academy of Child and Adolescent Psychiatry, vol. 37, no. 12, pp. 1294-1300, 1998.

[57] Y. B. Cho and N. Haslam, "Suicidal ideation and distress among immigrant adolescents: the role of acculturation, life stress, and social support," Journal of Youth and Adolescence, vol. 39, no. 4, pp. 370-379, 2010.

[58] V. Tuisku, M. Pelkonen, O. Kiviruusu, L. Karlsson, T. Ruuttu, and M. Marttunen, "Factors associated with deliberate selfharm behaviour among depressed adolescent outpatients," Journal of Adolescence, vol. 32, no. 5, pp. 1125-1136, 2009.

[59] A. M. Brausch and P. M. Gutierrez, "Differences in non-suicidal self-injury and suicide attempts in adolescents," Journal of Youth and Adolescence, vol. 39, no. 3, pp. 233-242, 2010.

[60] V. Tuisku, M. Pelkonen, L. Karlsson et al., "Suicidal ideation, deliberate self-harm behaviour and suicide attempts among adolescent outpatients with depressive mood disorders and comorbid axis I disorders," European Child and Adolescent Psychiatry, vol. 15, no. 4, pp. 199-206, 2006. 
[61] E. R. Galaif, C. P. Chou, S. Sussman, and C. W. Dent, "Depression, suicidal ideation, and substance use among continuation high school students," Journal of Youth and Adolescence, vol. 27, no. 3, pp. 275-299, 1998.

[62] N. Garnefski and E. J. de Wilde, "Addiction-risk behaviours and suicide attempts in adolescents," Journal of Adolescence, vol. 21, no. 2, pp. 135-142, 1998.

[63] P. Wu, C. W. Hoven, X. Liu, P. Cohen, C. J. Fuller, and D. Shaffer, "Substance use, suicidal ideation and attempts in children and adolescents," Suicide and Life-Threatening Behavior, vol. 34, no. 4, pp. 408-420, 2004.

[64] J. M. Light, J. W. Grube, P. A. Madden, and J. Gover, "Adolescent alcohol use and suicidal ideation: a nonrecursive model," Addictive Behaviors, vol. 28, no. 4, pp. 705-724, 2003.

[65] Suicide Prevention Resource Center, Suicide Risk and Prevention for Lesbian, Gay, Bisexual, and Transgender Youth, Education Development Center, Newton, Mass, USA, 2008. 


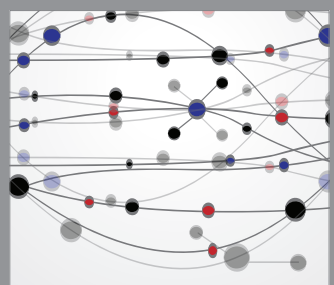

The Scientific World Journal
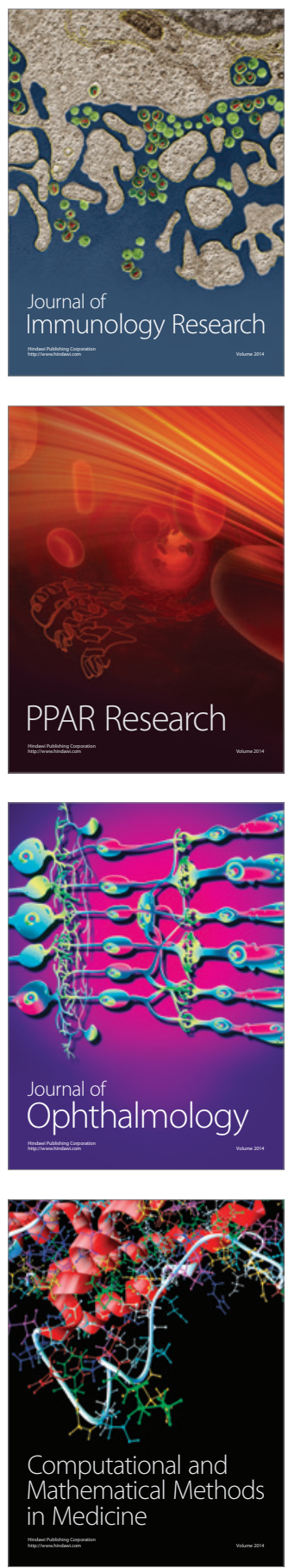

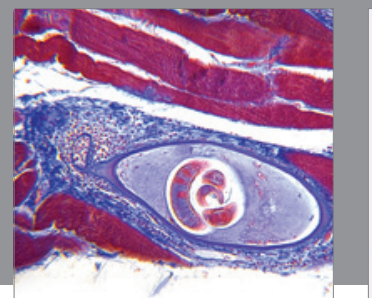

Gastroenterology

Research and Practice
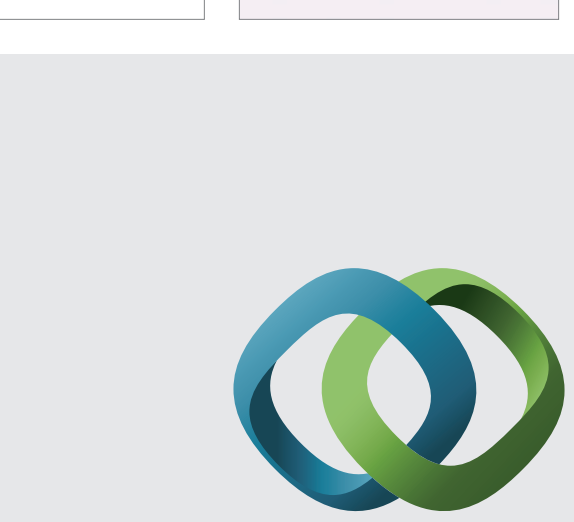

\section{Hindawi}

Submit your manuscripts at

http://www.hindawi.com
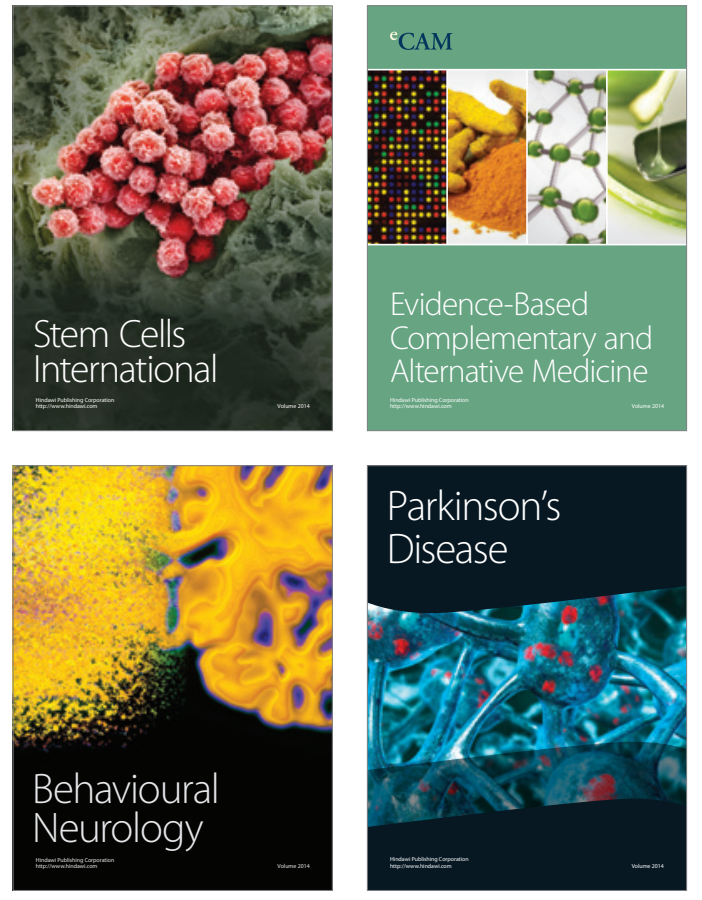
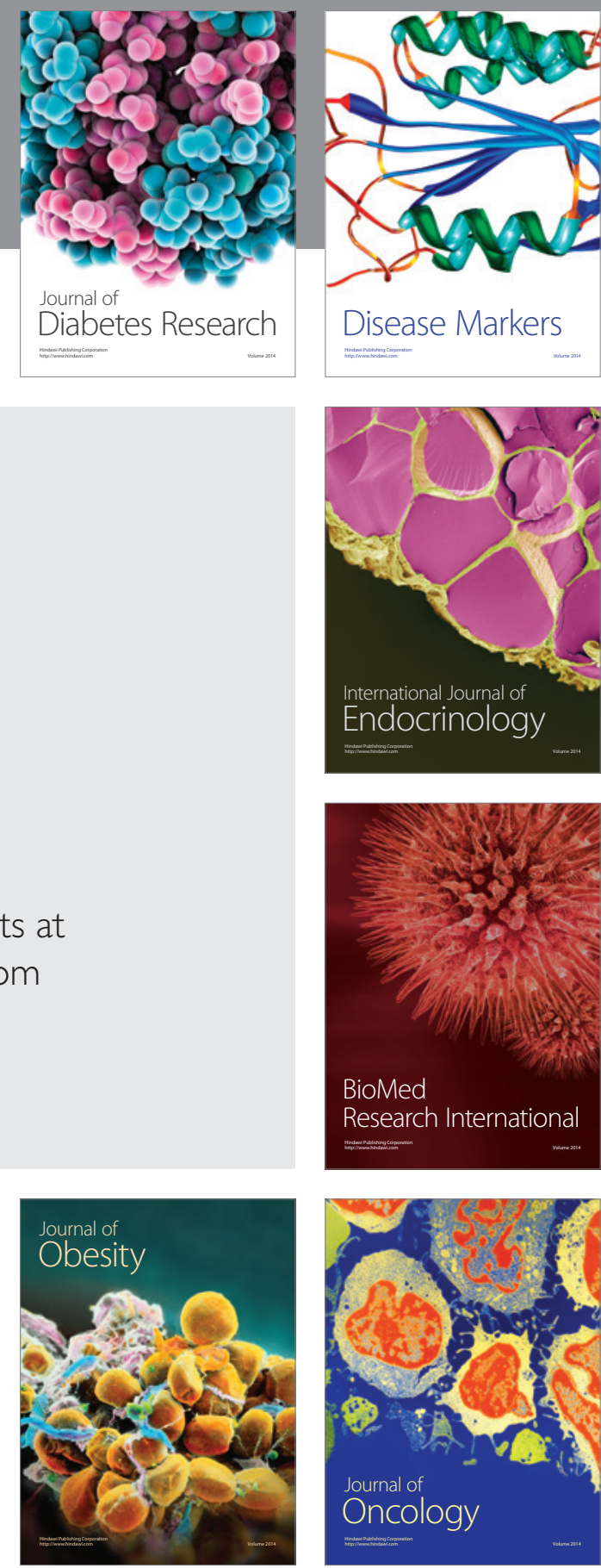

Disease Markers
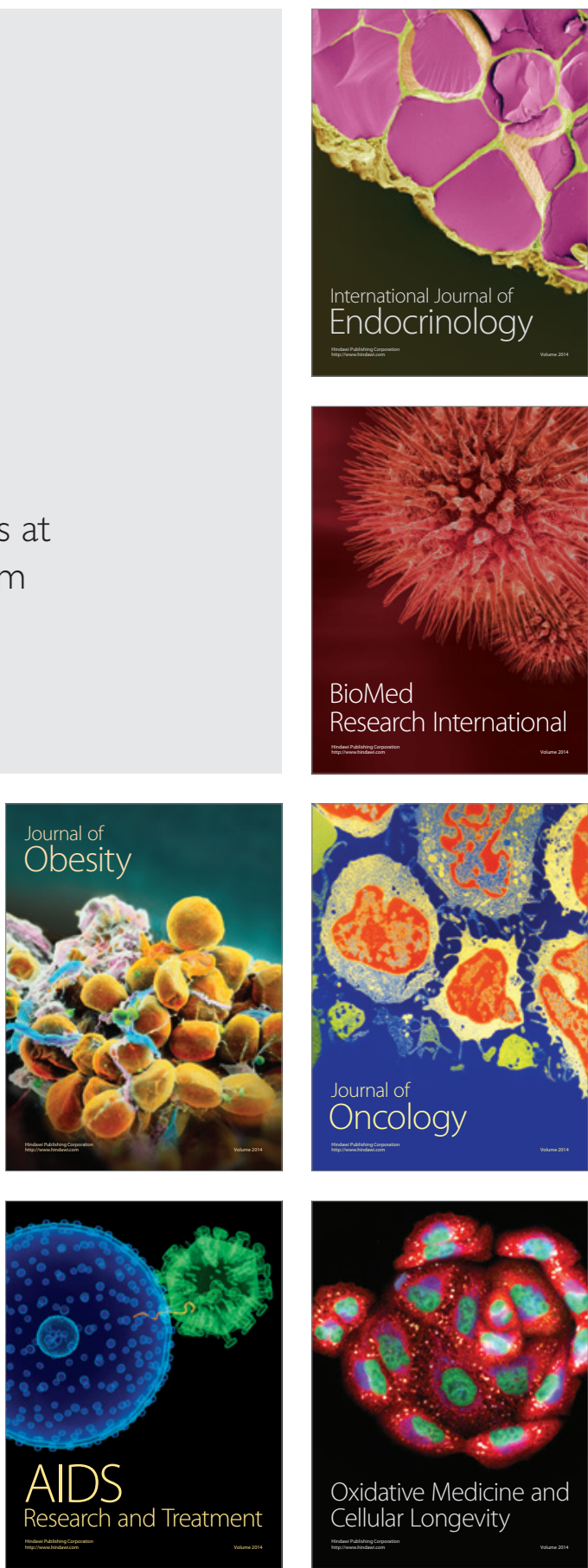